\title{
Documento
}

\section{Democracia, liberación y socialismo: tres alternativas en una*}

\author{
Pablo González Casanova
}

Instituto de Ciencias Sociais de Mexico

Ya lo ha dicho Eric Toussaint (2001): 1994 fue el año en que la rebelión zapatista de Chiapas "supo hablar de los problemas de opresión, hasta entonces percibidos como específicos, con un lenguaje universal que interpelaba a varias generaciones".

De allí en adelante los viejos y nuevos problemas locales y mundiales que se acentúan con la globalización neoliberal, empezaron a mostrar resistencias cada vez más profundas que se fueron identificando con etapas anteriores de las luchas contra el colonialismo, contra el capitalismo, contra el imperialismo, contra las dictaduras civiles y militares, y que se fueron insertando en las nuevas luchas de las etnias, de las mujeres, de los pobladores urbanos, de los ecologistas y los homosexuales. Seattle, en el año 2000, fue el sitio del reencuentro cada vez más explícito, cada vez más articulado, entre los "nuevos" y los "viejos" movimientos de los trabajadores y de

* Conferênia de abertura da $25^{\mathrm{a}}$ Reunião Anual da ANPEd, realizada em Caxambu, MG, de 29 de setetembro a 4 de outubro de 2002. los campesinos. El reencuentro mostró características acumulativas. En Porto Alegre del 2002 lo realmente nuevo de todos los movimientos de fines del siglo XX y principios del XXI apareció de una manera aún más clara. Como hicieron ver numerosos participantes, las alternativas, en una perspectiva histórica de corto y largo plazo tienen que plantear la necesidad de ser a la vez democráticas y socialistas, con respeto a la decisión de los pueblos y sus organizaciones y a la diversidad de culturas, de creencias, de teorías en lucha por la libertad, la justicia social y la paz.

La necesidad del socialismo en la democracia y de la democracia en el socialismo todavía no se manifestó como el sentido común de un pensamiento colectivo, plural y crítico. Pero la palabra democracia rompió muchas limitantes de sus falsos significados y otro tanto ocurrió con la palabra socialismo. La democracia se volvió el gobierno de un pueblo libre que discute y decide con sus ciudadanos y sus trabajadores los problemas que atañen a su relación con otros pueblos, con la naturaleza, con la cultura, con la sociedad, con la política, con la economía. Es un sistema-movimiento que se construye desde lo lo- 
cal hasta lo global, en medio de luchas y resistencias que lo llevan a articular organizaciones y redes en regiones enteras, al interior de las provincias y las naciones, y entre distintas provincias, naciones, culturas y continentes, todo sin que lo local deba preceder necesariamente a lo global, sino en que lo local y lo global del proyecto democrático y socialista, se van combinando en todo lo que se puede desde el principio, con respeto a las diferencias, ritmos, $\mathrm{y}$ variaciones, pero siempre con un concepto de unidad en la diversidad, que expresa lo universal en los derechos de los demás, ya sean pueblos, naciones, etnias, personas, organizaciones, costumbres o civilizaciones, cuidando siempre superar y controlar los intereses particulares que afectan a los generales y universales, y haciendo de la moral pública y del diálogo público parte de una nueva cultura de la creación, de la producción, de los estilos de consumo, y de las relaciones humanas con la naturaleza.

Como ha escrito Samir Amin (2001): "La aspiración democrática puede ser particular e integradora, particular cuando inspira a un movimiento que lucha contra una autoridad no democrática; integradora en tanto es concebida como un apoyo o palanca que contribuye a promover todas las demandas sociales". Al promover las demandas sociales, la aspiración democrática tiene que incluir la lucha contra toda forma de explotación y por una distribución del excedente que decidan los pueblos, los trabajadores y los ciudadanos, no sólo con libertad respecto a las megaempresas y sus asociados o subalternos sino respecto a los imperios, sus asociados y subalternos; no sólo frente a los remanentes de la discriminación y la exclusión colonial, sino frente a los remanentes de las concesiones populistas o clientelistas.

La aspiración democrática tiende así a acercarse, necesariamente, a la aspiración socialista y hay un camino para empezar a practicar la utopía socialista y democrática: es el camino del presupuesto participativo. Los brasileños han descubierto un nuevo tipo de utopías a las que podríamos llamar utopías prácticas. Leyendo al sociólogo brasileño Emir Sader (s.d.), sacamos las siguientes conclusiones sobre esta impor- tante aportación: el presupuesto participativo es a) un instrumento fundamental para la reforma democrática del Estado; b) una reformulación teórico-practica de las relaciones Estado-sociedad; c) una práctica en dirección de la soberanía popular; d) una práctica en la socialización de la política y el poder; e) una práctica en la solución dialogada y negociada de los problemas colectivos que se plantean en el interior de los pueblos, los trabajadores y los ciudadanos, y que se plantean en el exterior, con las clases y grupos dominantes en el capitalismo local o global y en los gobiernos o instituciones económico-políticas que los representan.

Marta Harnecker (s.d.) señala con razón, y como síntesis, que los presupuestos participativos son un espacio que rompe con "la lógica del lucro que mueve al capitalismo... Los presupuestos participativos crean espacios de participación popular o gestión democrática, es decir, crean espacios donde pueden irse conformando los sujetos protagónicos de la sociedad socialista del futuro". La misma autora esboza un problema que es de la mayor importancia para la política y la investigación, el problema de cómo acercarse desde las distintas propuestas a una sociedad alternativa. En su artículo sobre el primer Foro Social Mundial de Puerto Alegre, em Harnecker (s.d.), observa que éste logró "reunir en una misma actividad, gracias a la nueva cultura de la izquierda... a dos grandes corrientes de la misma: una que apuesta a acumular fuerzas por la vía del uso transformador de las instituciones y otra que busca hacerlo a partir de ir construyendo movimientos sociales autónomos".

De hecho, en nuestros días subsisten y se redefinen tres y no dos posiciones alternativas. A la vieja antinomia entre "reforma o revolución" se añade ese proceso más, posible y practicable, tal vez preferencial de que habla Martha Harnecker: la construcción de movimientos sociales autónomos. El problema es que si antes era discutible la antinomia "reforma o revolución" y podía pensarse en términos de combinar una y otra, hoy no sólo es discutible por eso sino porque cada vez cobra una mayor importancia teórica y práctica de la construcción de alternativas a 
través de movimientos sociales autónomos, que ni intentan tomar el Estado por la fuerza ni intentan insertarse en los aparatos políticos del Estado, así sean éstos partidos políticos de oposición con una ideología de izquierda. Este verdadero tercer camino no excluye a los demás y en ciertos momentos y lugares se llega a combinar con ellos o a concertar en acciones comunes. Hoy combinaciones y acciones comunes se dan de preferencia y cada vez que se puede con los movimientos que no intentan tomar por la fuerza el poder del Estado o con los partidos que buscan presionar e incluso imponer políticas que van contra el neoliberalismo y que coinciden con las demandas de los nuevos movimientos por el respeto a sus autonomías y por la instauración de regímenes de derecho que las incluyan en sus reformas del Estado.

La verdadera nueva vía a una alternativa que pueda adquirir características antisistémicas, es decir no sólo liberales, sino anticapitalistas, no sólo reformistas sino revolucionarias, en el sentido creador del concepto y en su sentido crítico de freno al dominio y a la apropiación del excedente y de los recursos por el capital corporativo y las empresas privadas, no ha sido objeto de suficientes análisis teóricos, y se ha prestado a errores de interpretación que habrán de ser desvanecidos en el futuro. La declaración de los zapatistas en que sostuvieron que no les interesa el poder del Estado no parece ser como creen muchos que tenga semejanza alguna con las posiciones aparentemente parecidas de los anarquistas. Más bien apunta a la creación de islas y archipiélagos de gobiernos locales autónomos y libremente articulados entre sí para la defensa de los intereses de sus comunidades y para el manejo democrático de sus problemas, incluido el manejo que corresponda a una lógica postcapitalista en relación a la distribución del excedente y a la asignación de la propiedad de medios de producción y bienes de uso común, familiar o privado. Con una aclaración, que la tendencia parece ser en éste, como en otros casos, a la combinación de propiedades públicas, sociales, comunales, familiares y privadas más que a la idealización excluyente de una de ellas.
La división de las alternativas en revolucionarias y reformistas exige otras aclaraciones como la de Amilcar Cabral (1975) cuando dijo que la revolución mundial será predominantemente pacífica con algunos episodios armados, o como la de Noam Chomsky (s.d.) cuando invitó a luchar, en todo lo que se pueda, en forma pacífica, pues en el terreno de la lucha por la opinión pública es donde los pueblos son y van a ser cada vez más fuertes incluso en esta etapa del neoliberalismo de guerra.

En cuanto a las alternativas que luchan predominantemente por reformas cabe destacar hoy las que tienden a cambiar las relaciones sociales opresivas e inequitativas a distintos niveles locales, nacionales o globales, y las que no modifican sustancialmente a ninguno de esos niveles los sistemas de apropiación y dominación, aunque frenen algunos de sus peores tendencias. La distinción entre las reformas a ciertas políticas y las reformas a las estructuras de dominación y apropiación tiene un inmenso significado. Estas últimas implican medidas que afectan a las clases y a los complejos de dominación-apropiación. Se trata de reformas mucho más difíciles de alcanzar en tanto quienes se benefician de la actual estructuración del sistema, ven en la reestructuración del mismo una pérdida de su poder de dominación y apropiación. Convencerlos de que esos cambios pueden ser útiles incluso para ellos en el largo plazo es prácticamente imposible hasta cuando se trata de preservar el sistema, no se diga ya cuando el proyecto estratégico que también ellos conocen, y al que temen biopsicológicamente - da sentido a las reformas de acumulación de fuerzas antisistémicas, hecho que también conocen. El problema se vuelve hoy más difícil cuando, patológicamente, los líderes más conservadores de las grandes potencias y sus subordinados creen que una posición conquistadora y guerrera (the american way han dicho) los favorece tanto que son capaces de iniciar nuevas aventuras coloniales como en Kosovo, Afganistán y Palestina, mientras en la construcción de su Imperio (en su Empire building) llegan a amenazar velada y abiertamente de ataques nucleares a China, Rusia, Corea del Norte, Irán, Irak y 
Libia, esto es, al mundo entero incluida la población de Estados Unidos y aledaños, en que de acuerdo con sus propios cálculos sobre una llamada "guerra nuclear racional" los Estados Unidos "sólo perdería" (sic) "20 millones de habitantes...".

Para cambiar la actual correlación de fuerzas a favor de la humanidad, y en espera de que cambie por las distintas contradicciones internas y externas de la Tríada Imperial, es necesario profundizar en las dos principales reformas de estructuras que transformarían la actual correlación de fuerzas internacional e intranacional a favor de los pueblos, los trabajadores y los ciudadanos: la primera es la cancelación de la deuda externa, la segunda, el reconocimiento y fortalecimiento de los derechos de autonomía de las etnias y las poblaciones, de las localidades, los barrios y los municipios, de las ciudades y conglomerados urbanos, de las redes y regiones culturales, ecológicas y socioeconómicas, con derecho a vincularse entre sí dentro y fuera de los límites de las naciones-Estado, en las viejas y nuevas regiones multinacionales, subcontinentales, continentales y transcontinentales.

La deuda externa constituye el cemento del poder imperial de nuestro tiempo encabezado por las megaempresas y las grandes potencias. La deuda externa no sólo es la base para crear nuevas relaciones de dependencia de los gobernantes y de las clases dominantes de las periferias mundiales, sino la base para renovar permanentemente esa dependencia haciendo de ella el elemento principal para la implantación de políticas económicas, sociales y culturales de los países endeudados. Entre esas políticas está la renovación y la ampliación obligada de una deuda impagable que no sólo organiza y jerarquiza las formas de la dependencia sino privatiza la recaudación de impuestos, al hacer del grueso de los mismos fuente para el pago del interés y del principal. La deuda externa sirve también para privatizar la política de egresos. De hecho genera una política de privatización de propiedades públicas y sociales que fortalece los nuevos poderes y propiedades del Imperio, de sus corporaciones y de sus asociados. La política de privatización de empresas públicas es una de las mayores fuentes de corrupción organizada, que también se da con el crimen organizado y sus correspondientes auxiliares del sector público. La corrupción sistémica es generadora de nuevas grandes fortunas y saqueos. Ayuda a establecer vínculos de socios, de corporaciones, de élites o de mafias, y a extender el carácter transnacional de las clases dominantes que son parte de las redes del imperio global y del capitalismo mundial. Esas redes constituyen jerarquías que fortalecen a los complejos dominantes y sus asociados con políticas de altos salarios y prestaciones para los funcionarios privados y públicos del "sector moderno" y corporativo, cuyos niveles de vida y consumo no sólo contrastan con la creciente población informal, sino con los sectores medios empobrecidos. La red de complejos, megaempresas y sus socios también se fortalece mediante sistemas de estímulos que fomentan el "individualismo" y la "solidaridad" que coopta y corrompe selectivamente a líderes y poblaciones marginadas y excluidas dividiéndolos en colaboracionistas o rebeldes, en pobres y extremadamente pobres.

Romper la actual armazón de poder y saqueo, complicidad y mediatización exigiendo que se cancele la deuda externa equivale a proponer que se termine con la globalización neoliberal del actual capitalismo organizado. Por ilusorio que parezca ese objetivo no deben abandonarse las demandas y presiones para la cancelación de la deuda externa, al contrario; pero al insistir en que se tome esa medida, que por lo demás ya se ha tomado en otras épocas de la historia del capitalismo, no cabe ignorar que la cancelación de la deuda externa constituye una amenaza al sistema de poder que el complejo militarindustrial y el Grupo de los Siete han construido en las últimas décadas para la reestructuración global del capitalismo, del imperio y el imperialismo, del colonialismo y el neocolonialismo.

Por otra parte es necesario considerar que el sistema dominante no tendrá más alternativa como "sistema inteligente" (si logra serlo) que cancelar la deuda externa para una transición más o menos pacífica hacia un sistema de sobrevivencia humana cuya construc- 
ción se definirá sobre todo en función de luchas y negociaciones que se libren al respecto, y en las que se aduzcan con toda la fuerza necesaria y con el mayor respaldo empírico y político las consecuencias de no hacerlo. La extraordinaria labor realizada por el Comité para la Anulación de la Deuda del Tercer Mundo (CADTM), merece el mayor apoyo de las fuerzas progresistas y liberadoras partidarias de la paz mundial.

En cuanto a la autonomía de los pueblos, ciudades y regiones, empezando por la autonomía de las localidades y su articulación virtual o actual, es un proyecto generador de nuevas relaciones sociales, cuyo carácter democrático comprende una nueva construcción del poder y la política, capaz de extenderse a la cultura, la sociedad y la economía y de ponerse en práctica en las instituciones del programa y el presupuesto participativo. En todo caso esa autonomía, en sus lineamientos más amplios, no sólo ratifica la necesidad del respeto al pluralismo ideológico, político, religioso, cultural, sino del respeto a la autonomía de la persona humana en sus sentimientos, creencias, placeres e intelecto. Es además la base de una organización de la soberanía-del-pueblo-hecho-de muchospueblos, que constituye la genuina soberanía de las naciones y de los estados-nación. La lucha por la soberanía de los gobiernos locales que sube en la escala hacia las autonomías regionales, nacionales y mundiales, corresponde sin duda a la construcción de un poder alternativo a distintos niveles. Debiendo formar parte de la reforma de los estados, la estructuración de autonomías territoriales, sectoriales, sociales, económicas, culturales y políticas abre una historia nueva, alternativa y emergente cuyas capacidades de diálogo y negociación irán forjándose con los cambios en la correlación de fuerzas desde lo local hasta lo global, desde las regiones y las naciones hasta una nueva globalización democrática respetuosa de las autonomías y las soberanías a nivel internacional y en las organizaciones internacionales.

En todo caso, a esas grandes alternativas se añade la posibilidad y la necesidad de añadir otras con distintos criterios teóricos y prácticos. Amin (2001) ha identificado los movimientos alternativos en función de sus aspiraciones. Los ha clasificado en cinco corrientes: (1) los que aspiran a una democracia política, regida por la ley y por la libertad intelectual, (2) los que aspiran a la justicia social; (3) los que aspiran al respeto a varios grupos y comunidades, (4) los que aspiran a un mejor manejo ecológico, y (5) los que aspiran a una posición más favorable en el sistema global. Esta clasificación da una primera idea de la diversidad de las alternativas emergentes y de los planteamientos que los movimientos sociales de nuestro tiempo formulan en lo general. Esas diferencias en las aspiraciones requieren un respeto a la diversidad e irse acercando en los objetivos coincidentes al tiempo que se precisan y profundizan los objetivos y requerimientos para alcanzarlos. El propio Amin (idem) ha planteado la necesidad de "la convergencia en la diversidad", ya no sólo desde el punto de vista de las aspiraciones más generales sino de las creencias, ideologías, teorías, estrategias y tácticas, y de la distinta capacidad de realizar acciones coordinadas que contribuyan a profundizar y radicalizar el pensamiento y la acción efectiva de colectividades crecientes que se unan en lo diverso. En esa dirección, Amin plantea una alternativa frente a lo que él llama "un apartheid en escala global" forjado por el neoliberalismo. Su propuesta implica un paso muy profundo: "la construcción de una globalización post-capitalista basada en la igualdad entre los pueblos, las comunidades, los estados y los individuos" (idem), objetivo inalcanzable e irrealizable en el sistema capitalista mundial.

Houtart (s.d.) distingue en las alternativas aquéllas que se acercan a una corriente neokeynesiana y las que se insertan en la corriente postcapitalista. El autor se propone precisar las alternativas que son creíbles dentro del capitalismo y las que sólo son creíbles fuera del capitalismo. De su planteamiento y de otros planteamientos se desprenden varias reflexiones y precisiones que pueden ahorrar innecesarios debates.

Primero: existen alternativas en el sistema y para cambiar lo, hecho comprobable por las variaciones 
de la globalización entre unos países y otros, variaciones que en gran medida dependen del comportamiento de pueblos y gobiernos, y de la organización y fuerza que logren imponer aquéllos y sus más directos representantes.

Segundo: la búsqueda y construcción de alternativas no es un problema tecnocientífico nada más. Depende sobre todo del "actuar colectivo" a corto y mediano plazo, con perspectivas tácticas y estratégicas que cambien las relaciones sociales a favor de pueblos, trabajadores y ciudadanos y aumenten su poder en los órganos políticos del Estado, en las bases sociales del Estado y en la lucha por el control del mercado o de parte del mercado, empezando por el control de los mercados internos y de la autosuficiencia alimentaria y en los bienes y servicios para la sobrevivencia, para la resistencia.

Tercero: es necesario distinguir entre las reformas de quienes quieren salvar al sistema (estilo Georges Soros) y las de quienes quieren también sustituir al Sistema (ATTAC, CADTM). En algunas propuestas pueden acercarse ambas posiciones como en el impuesto al capital especulativo. Esas coincidencias deben aceptarse y mantenerse como base de futuros avances que permitan sustituir los enfrentamientos por negociaciones y asociaciones para que las fuerzas populares organizadas mantengan e incluso incrementen su autonomía.

El problema de las alternativas se plantea a un nivel más profundo en los enfrentamientos de la lógica neokeynesiana con un mercado regulado por el Estado, y la lógica neoliberal del mercado y el Estado regulados por las megaempresas y los complejos empresariales. Las afinidades con los movimientos neokeynesianos y desarrollistas pueden ser base de alianzas en torno a políticas particulares, siempre que no alteren el proyecto principal de creación de fuerzas autónomas alternativas en la sociedad civil y en la sociedad política.

La crisis de las políticas de cooptaciones y corrupciones de las organizaciones y gobiernos neoliberales, socialdemócratas, desarrollistas, populistas y excomunistas planteará la lucha contra el ser- vilismo, el conformismo y el cinismo en un primer plano político-moral. De ser vencidas las organizaciones alternativas mediante la cooptación y la corrupción de sus miembros, los nuevos contingentes que asuman la creación de alternativas, o la simple resistencia, adquirirán características más y más violentas tanto frente a los gobiernos representativos del neoliberalismo de guerra como frente a las fuerzas moderadas que sigan luchando al lado de los pueblos, los trabajadores y los ciudadanos. La acusación prevista de "terroristas" y la activación del aparato represivo, no sólo presionarán sobre los grupos y redes de resistencia y acción armada sino contra los grupos de la oposición que actúen en la legalidad restringida, y que serán acusados de "agentes" y declarados también ilegales, si el apoyo cívico no es muy fuerte y muy amplio.

En todo caso es de prever el incremento de la lógica postcapitalista, antisistémica, con relaciones sociales en que los pueblos, los trabajadores y los ciudadanos organicen el poder de decidir en función de las necesidades de las mayorías, expresadas democráticamente, a distintos niveles de autonomía y de soberanía frente a las corporaciones y los gobiernos, frente al imperio o los imperios que busquen despojarlos de la autonomía y soberanía logradas como individuos, comunidades, pueblos y naciones en luchas anteriores y en las actuales.

La difusión o generalización de la lógica postcapitalista, antisistémica como modo de dominación, de mediación, de consumo, y no sólo de producción, presentará variaciones universales según las formaciones de los distintos sistemas intranacionales, internacionales, transnacionales y de la globalización. En medio de esas diferencias se descubrirán semejanzas y simpatías no sólo en el terreno intelectual y en las medidas políticas y sociales, culturales y económicas a tomar, sino en el campo de las solidaridades y las articulaciones de redes para acciones concretas desde lo local hasta lo global.

Cuarto: Las políticas alternativas a corto plazo implicarán formulaciones y reformulaciones de programas de lucha y reestructuraciones y rearticulacio- 
nes del "actuar colectivo". El incremento de fuerzas será considerablemente distinto al que se quiso articular en torno a una clase, una ideología y un partido. La lucha por la hegemonía planteará problemas de unidad en la diversidad desde lo local hasta lo universal. La lógica de las "ausencias" de actores, de conceptos, valores, técnicas, políticas que es necesario incluir o respetar, y la de las "traducciones" de idiomas, culturas, civilizaciones, así como la de las "interpretaciones" opuestas a partir de una misma creencia o ideología tienen que deshacerse de los remanentes característicos de un pensar autoritario, dogmático, descalificador, y acentuar las características del diálogo-debate en que cada participante hace suyo, como primer objetivo, el aprender del otro y con el otro, empezando por el "hermano" o el "compañero", el "coterráneo" o el "paisano" o el "sin rostro", y llegando al "extranjero" y hasta al "adversario que puede dejar de serlo", en una lógica que asume fuerzas y conciencias para alcanzar determinados objetivos.

En la lucha por alternativas a corto plazo será necesario considerar sus efectos inmediatos y centrales, y los laterales o secundarios, y entre estos no sólo las reacciones del enemigo frente a posibles triunfos, sino el reforzamiento o debilitamiento de las propias fuerzas, en particular de la propia autonomía o soberanía. Toda política de pactos o de alianzas tendrá que dar prioridad a este tipo de razonamientos: No debilitar la autonomía ni la soberanía. Pensar cuáles serán los efectos indirectos de cualquier acuerdo con las fuerzas dominantes y sus sistemas o organizaciones mediatizadoras.

Quinto: en las políticas alternativas a corto plazo destacan en forma casi universal varias luchas que operan en formas particulares o como parte de movimientos que las articulan: $1^{\circ}$. la lucha por la negociación de la deuda externa; $2^{\circ}$. la lucha en defensa del sector público, social y cultural y de la propiedad pública, social y cultural, así como de los servicios gratuitos de seguridad social, educación, salud, alimentación; $3^{\circ}$. la lucha contra la privatización de las empresas públicas, estatales, paraestatales y sociales, y contra las transferencias al capital corporativo y extranjero de infraestructuras, recursos energéticos y otros recursos naturales, como el agua; $4^{\circ}$. la lucha contra la eliminación de subsidios sociales y contra su sustitución por políticas de excensiones, concesiones, subsidios y avales a las megaempresas y sus asociados; $5^{\circ}$. la lucha contra las políticas de encarecimiento, enrarecimiento y fijación de plazos en los créditos, contrarios a la producción de bienes primarios y secundarios y de servicios por las pequeñas y medianas empresas; $6^{\circ}$. la lucha contra las políticas monetaristas de carácter recesivo; $7^{\circ}$. la reducción de las importaciones de armas y equipos militares y el incremento de importaciones de bienes de producción, en especial para las zonas marginadas; $8^{\circ}$. la lucha por una política financiera, tecnológica, de empleo, distribución y consumo que priorice el mercado interno, y el sector nacional y social; $9^{\circ}$. la lucha por la defensa de los campesinos y agricultores frente a la competencia desigual y subsidiada de los agricultores de Estados Unidos y el Grupo de los Siete; $10^{\circ}$. la lucha contra la "des-regulación" y pérdida de derechos de los trabajadores; $11^{\circ}$. la lucha contra el nuevo reparto de los territorios y recursos naturales mediante planes abiertamente militares, o que se realizan al amparo de supuestos acuerdos y tratados como el Area de Libre Comercio de las Américas (ALCA): el plan de la "frontera" para la integración de los estados del norte de México a la economía estadounidense; el Plan Puebla-Panamá para la redefinición de los dos Méxicos, el del Sur y el del Norte, y para la redefinición de América Central y de las llamadas "Repúblicas Bananeras"; el "Plan Colombia", punta de lanza del control de la Amazonia y parte del cerco a Brasil apoyado también con la ruptura del "Mercosur", el colapso de la Argentina y el liderazgo creciente del Chile que construyó Pinochet y que cooptó a la clase política y a la intelectualidad chilena. A la resistencia a esos planes se añaden muchas otras en defensa de la Revolución Cubana y de los pueblos indígenas de América Latina, y muchas más a favor de Palestina, Afganistán y el mundo entero cada vez más amenazados por la nueva política del neoliberalismo de guerra, que inició el gobierno de 
los Estados Unidos a raíz de los acontecimientos del 11 de septiembre, un nuevo motivo de declaración de guerra parecido al hundimiento de un barco que desató la guerra de 1898 contra España, o al ataque a Pearl Harbor que decidió el ingreso de Estados Unidos a la Segunda Guerra Mundial.

En este punto es necesario insistir en que el contexto de todas las alternativas ha variado considerablemente desde el inicio de la "IV Guerra Mundial" en septiembre del 2002. El neoliberalismo de guerra no sólo redefine las luchas contra las organizaciones que resisten en forma armada y que en general caen bajo la categoría de "terroristas" indiciados y clasificados así por los gobiernos, en especial por el de Estados Unidos.

El neoliberalismo de guerra también afecta fuertemente las corrientes que luchan por la aplicación de la Carta de las Naciones Unidas y de las Constituciones Políticas de los Estados; afecta a aquellas fuerzas que luchan en los parlamentos y congresos por reformas políticas, económicas, sociales y culturales, y a aquéllas que luchan por la construcción de alternativas, por ejemplo a partir de gobiernos locales autónomos y sus redes, o de presupuestos participativos y de organizaciones democráticas y plurales de campesinos sin tierra, o en defensa de sus territorios, sus tierras y fuentes de producción y aprovisionamiento.

El neoliberalismo de guerra defiende por las armas una política que ya no puede defender por las argumentaciones de "la ciencia única" ni con los enredos del Banco Mundial quien critica al neoliberalismo y sigue exigiendo que se apliquen todas y cada una de sus medidas. El neoliberalismo de guerra enfrenta una crisis de credibilidad, de gobernabilidad y de sobreproducción con una política de guerra e intimidación que le permite reformular las presiones de los peores momentos de la guerra fría sólo que acusando ahora de "terroristas" a quienes antes acusaba de "comunistas".

El neoliberalismo de guerra permite al capital corporativo, a sus megaempresas y redes controlar más directamente a los propios gobernantes, ya sea ayudándolos a triunfar en las elecciones y en las campañas comerciales con que compran las imágenes y las conciencias para orientar el voto, ya sea presionándolos para que apliquen cada vez más duramente las políticas neoliberales y enfrenten "con firmeza y habilidad" a sus pueblos, electores y trabajadores depauperados, desempleados y excluidos.

El neoliberalismo de guerra le permite al capital corporativo y sus gobiernos reforzar la jerarquía mundial de poder y reforzar los alineamientos, sometimientos y arbitrariedades de las fuerzas neoconservadoras que abandonan la política de disuasión, y pasan a la de agresión, expansión e integración por todos los medios propagandísticos y publicitarios disponibles y por todos los medios de destrucción de baja y alta intensidad, convencionales y no convencionales, altamente sofisticados y de fácil empleo, con amenazas que simulan o expresan la locura de usar las armas nucleares, y con temores oficiales y subrepticiamente difundidos de que grupos y gobiernos terroristas, incluido el de Estados Unidos, conduzcan a una guerra bactereológica.

El neoliberalismo de guerra permite incrementos colosales en las inversiones y gastos de guerra que sin embargo no constituyen suficientes estímulos para reactivar la economía y atenuar los graves peligros de la recesión. Por eso el Soberano Global toma medidas y usa términos que mantienen a la humanidad al borde de la guerra y prepara una mentalidad universal y existencial de pre-guerra.

El neoliberalismo de guerra permite romper el estado de derecho tanto en relación al orden jurídico mundial, a la Carta de las Naciones Unidas y a los principales acuerdos internacionales, como en relación al orden constitucional de los países periféricos y de los propios países centrales. A los fenómenos de corrupción estructural, de extorsión financiera y comercial, de sometimiento mediante la privatización de los sistemas impositivos por la vía del endeudamiento externo se añaden medidas expansionistas en el terreno de las bases militares, de las fuerzas militares y paramilitares, de las ocupaciones de territorios y de la desnacionalización de los sistemas de producción y distribución, así 
como de los medios de comunicación de masas, de los transportes y de las fuentes energéticas.

En todo el mundo el neoliberalismo de guerra tiende a mostrar el carácter profundamente antidemocrático del capital corporativo, de las empresas metropolitanas y periféricas, y de los imperios y gobiernos que lo emplean. La llamada "Guerra por la libertad perdurable", que fue declarada con el pretexto de acabar con el terrorismo, no sólo acaba con el derecho de los pueblos a la libre autodeterminación que en el pasado alcanzaron contra el colonialismo y el imperialismo, sino acaba con muchas garantías individuales y con libertades cívicas hasta hace poco relativamente respetadas en las metrópolis y en algunos países de la periferia.

El neoliberalismo de guerra permite realizar acciones de liderazgo y expansión imperial forzando acuerdos y pactos con los distintos gobiernos asociados y dependientes, en condiciones en que los Estados Unidos, como líder principal, hace que las demás potencias se vean envueltas en sus líneas políticas de guerra, sin que participen en la discusión y decisión de las mismas, sino más bien como apoyo obligado o como oposición moderada. En el caso de los gobiernos periféricos e incluso en mucho de los gobiernos centrales el apoyo se vuelve abiertamente servil.

El neoliberalismo de guerra fortalece la política de dominación compartida y jerarquizada de los procesos de globalización que cimentó en especial la deuda externa; pero los Estados Unidos mantiene, en todos los casos, una supremacía militar indiscutible, fenómeno que sólo tiene como límite el peligro inevitable de una "guerra de destrucción mutua" con el que se está jugando en la integración del nuevo imperio mundial, mediante una representación de anglohitlerismo que recurre a la retórica del hombre normal, enérgico y decidido, sea Bush o Sharon.

El neoliberalismo de guerra actualiza y profundiza el desarrollo del capitalismo global y del dominio del mundo y de sus distintas regiones por las macroempresas auxiliadas de los organismos internacionales y de las grandes potencias, así como de sus aliados de subsidiarias, de oligarquías, mafias, élites y mandos militares y paramilitares, de servicios de seguridad y servicios de información pública y propaganda, que integran las redes de dominación.

El neoliberalismo de guerra provoca durante un tiempo efectos lineales de dominación y expansión del capitalismo, el imperialismo y el capitalismo tardío, a costa del desprestigio y debilitamiento de sus proyectos de "progreso" o "desarrollo" y por supuesto de sus proyectos de democracia liberal o de "democracia capitalista" como orgullosamente la llamaba Fukuyama. Entre los efectos indirectos del neoliberalismo de guerra también aparece una mayor radicalización del pensamiento alternativo y de las categorías que este emplea, entre las que empiezan a sobresalir cada vez más a las del sistema de producción y dominación capitalista, las del imperialismo y el colonialismo con sus nuevas estructuraciones, así como las alternativas de una democracia universal participativa y representativa estrechamente asociada a la liberación y al socialismo.

El desarrollo futuro de las alternativas tendrá muy probablemente un carácter no lineal en que pequeñas causas producirán efectos desproporcionados. Ese futuro comportamiento es posible e inevitable, casi necesario. Lo que puede variar es el desenlace de por lo menos dos luchas, la de una alternativa que entre guerras y negociaciones permita la democracia como liberación y socialismo, y la de una alternativa que con las fuerzas de la paz y las negociaciones también permita la sobrevivencia de la humanidad y del planeta. El problema de la negociación sin claudicación y con acumulación de fuerzas alternativas democráticas, liberadoras y socialistas en lucha por la paz y por la vida, es el problema central del futuro inmediato. El comportamiento patológico de las fuerzas dominantes hace particularmente difícil cualquier transición sistémica; pero por ningún motivo impide descartar que en un tiempo difícil de precisar - venga una nueva etapa de grandes revoluciones. En todo caso, las alternativas a la globalización neoliberal lucharán por una globalización alternativa en que la democracia, la liberación y el socialismo constituirán una 
misma lucha hecha de las tres luchas. El movimiento no sólo cambiará necesariamente esa lucha y esas otras tres luchas. También cambiará los procesos de reforma, revolución y construcción, y los de conflicto y consenso, enfrentamiento y negociación. Las combinaciones de las mismas requieren estudios concretos, históricos y teóricos a los que es necesario dar una prioridad que hasta ahora no les hemos acordado.

PABLO GONZÁLEZ CASANOVA, primeiro sociólogo mexicano a realizar estudos sociopolíticos que geraram o clássico La democracia em Mexico, foi diretor do Faculdade de Ciências Políticas e Sociais e reitor da Universidade Nacional do México UNAM. Realizou estudos sobre o colonialismo interno, revelando como é produzida a colonização ou a dominação nos países chamados desenvolvidos, do Terceiro Mundo ou emergentes, no contexto das relações assimétricas entre esses países e os países desenvolvidos. É um dos intelectuais que mais se aproxima do movimento indígena, apoiando os zapatecas. Atualmente desenvolve projeto de construção de conceitos, junto ao Programa de Pós-Graduação sobre Pensamento e Cultura, na Universidade da Cidade do México.

\section{Referências bibliográficas}

AMIN, Samir, (2001). Le Congres Mondial contre le racisme (*). Durban, sepetiembre.

CABRAL, Amilcar, (1975). Unité et lutte. Paris: Maspero.

CASTRO, Fidel, (1992). Un grano de maíz. La Habana: Oficina de Publicaciones del Consejo de Estado.
CHOMSKY, Noam, (s.d.). On the bombing; Israel \& EU do apartheid a guerra aberta; The real "peace process" and the real prospects; ¿Por qué el Foro Mundial? y un mundo sin guerras es posible. $(*)$

SANTOS, Boaventura de Souza, (s.d.). ¿Cuáles son los límites y posibilidades de la ciudadanía planetaria? y As tensoes da modernidade. $(*)$

GONZÁLEZ CASANOVA, Pablo, (2001). Tendencias sistémicas y movimientos antisistémicos. Septiembre, mimeo.

HARNECKER, Martha, (s.d.). Articular la izquierda partidaria e izquierda social para construir un gran bloque social antineoliberal. $(*)$

HOUTART, François, (s.d.). Des alternatives crédibles au capitalisme mondialise. (*)

INFORME DE LA COMISION, (2002-2002). Global Trends 2015. A Dialogue about the Future with Nongobernment Experts. Washington: National Intelligence Council.

SADER, Emir, (s.d.). Soberania e democracia na era de hegemonia norte-americana $(*)$

SOROS, Georges, (1998). La crisis del capitalismo global; la sociedad abierta en peligro, México: Plaza y Janés.

TOUSSAINT, Eric, (2001). Después de Genova mirando hacia el futuro, acceso en 1 de agosto.(*)

WALLERSTEIN, Immanuel, (1997). El futuro de la sociedad capitalista, Barcelona: Icaria.

Recebido em setembro de 2002

Aprovado em novembro de 2002

(*) Se pueden consultar en: http:/www.forumsocialmundial.org.br/esp/tbob.asp 